\title{
Article
}

\section{Mental and perceptual feedback in the development of creative flow}

Cseh, Genevieve M., Phillips, Louise H. and Pearson, David G.

Available at http://clok.uclan.ac.uk/14230/

Cseh, Genevieve M., Phillips, Louise H. and Pearson, David G. (2016) Mental and perceptual feedback in the development of creative flow. Consciousness and Cognition, 42 . pp. 150-161. ISSN 1053-8100

It is advisable to refer to the publisher's version if you intend to cite from the work. http://dx.doi.org/10.1016/j.concog.2016.03.011

For more information about UCLan's research in this area go to

http://www.uclan.ac.uk/researchgroups/ and search for <name of research Group>.

For information about Research generally at UCLan please go to http://www.uclan.ac.uk/research/

All outputs in CLoK are protected by Intellectual Property Rights law, including Copyright law. Copyright, IPR and Moral Rights for the works on this site are retained by the individual authors and/or other copyright owners. Terms and conditions for use of this material are defined in the policies page.

\section{CLoK}

Central Lancashire online Knowledge www.clok.uclan.ac.uk

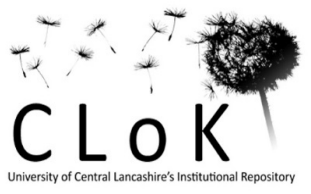




\section{AUTHORS' ACCEPTED MANUSCRIPT:}

This is a preprint of an article accepted for publication in the journal Consciousness \& Cognition [copyright Elsevier]. Consciousness \& Cognition is available at:

http://www.journals.elsevier.com/consciousness-and-cognition/

Please cite this paper as:

Cseh, G. M., Phillips, L. H., \& Pearson, D. G. (in press). Mental and perceptual feedback in the development of creative flow. Consciousness and Cognition.

\section{Mental and perceptual feedback in the development of creative flow}

Genevieve M. Cseh ${ }^{\mathrm{a}, 1}$, Louise H. Phillips ${ }^{\mathrm{a}}$, and David G. Pearson ${ }^{\mathrm{b}, *}$

a School of Psychology, University of Aberdeen, Aberdeen, UK

b Department of Psychology, Anglia Ruskin University, Cambridge, UK

*Correspondence concerning this article should be addressed to Dr. David Pearson, Department of Psychology, Anglia Ruskin University, East Road, Cambridge, United

Kingdom, Tel: +44 (0)845 196 2674, Fax: +44 (0), E-mail: david.pearson@ anglia.ac.uk. 


\begin{abstract}
Sketching is considered by artists and designers to be a vital tool in the creative process. However, research shows that externalisation during the creative process (i.e., sketching) is not necessary to create effectively. This study examines whether sketching may play a more important role in the subjective experience of creativity by facilitating the deeply focused, optimal state of consciousness termed 'flow' (being 'in the zone'). The study additionally explored whether sketching affects flow by easing cognitive load or by providing a clearer sense of self-feedback. Participants carried out the creative mental synthesis task (combining sets of simple shapes into creative drawings), experimentally simulating the visual creative process. Ideas were generated either mentally before committing to a final drawing, or with external perceptual support through sketching, and cognitive load was varied by using either three- or five-shape sets. The sketching condition resulted in greater experience of flow and lower perceived task difficulty. However, cognitive load did not affect flow and there was no interaction between load and sketching conditions. These findings are the first to empirically demonstrate that sketching increases flow experience, and that this is not dependent on an associated reduction in overall working memory load.
\end{abstract}




\section{Introduction}

Sketching has long been considered essential to the creative process (Kleiner, 2008/2014), and as such is taught extensively as a fundamental skill in art and design education programmes (Efland, 1990). However, artists and designers may over-emphasise the value of sketching in enhancing creativity, with purported benefits of sketching to performance supported by only patchy and contradictory evidence (Anderson \& Helstrup, 1993; Bilda, Gero, \& Purcell., 2006; Kokotovich \& Purcell, 2001; Verstijnen, Hennessey, van Leeuwen, Hamel, \& Goldschmidt, 1998a; Verstijnen, van Leeuwen, Goldschmidt, Hamel, \& Hennessey, 1998b). Nonetheless, creator attitudes reflect a belief that sketching must facilitate creativity and when sketching is thwarted the end result is often frustration (Bilda et al., 2006). Despite this disconnect between creators' attitudes and evidence suggesting that sketching does not greatly improve creativity, little has been done to investigate how sketching might influence the subjective experience of creating.

In their protocol analysis study with architects, Bilda et al. (2006) found that sketching and blindfolded architects were able to produce equally creative and practical designs, despite claiming that sketching was vital to their process. When interviewed, the architects perceived three main benefits of sketching: 1) it helps clarify, reinterpret, and verify ambiguous mental representations (synthesizing); 2) it eases tensions on memory resources (image maintenance); and, perhaps as a consequence of the previous two factors, 3) it increases confidence in creative abilities. Bilda et al. conclude: "Sketching makes design thinking easier by 'seeing it' and 'storing it'. In other words, sketching puts much less load on the cognitive processes needed to design" (p. 607).

How the creative act feels to the creator is important. Csíkszentmihályi (1975; $1990 / 2002$; 1996) proposed that the creative act is intrinsically driven by a desire to 
experience a highly positive subjective immersion within the process that has been termed flow. The concept of flow is similar to previous concepts of peak experience (Maslow, 1959; Privette \& Bundrick, 1991) and is more commonly referred to as being 'in the zone'. It is believed to have positive consequences in terms of wellbeing and enhancement of performance, however causal directions of these relationships are unclear (Landhäußer \& Keller, 2012), and the links are not always supported by empirical evidence (Cseh, Phillips, \& Pearson, 2015).

Sketching may facilitate certain prerequisite components of flow (Csíkszentmihályi, 1990/2002). Specifically, sketching may help provide less ambiguous self-feedback, facilitate a feeling of effortless attention and control by lightening burdens on cognitive load, and providing an increased sense of competence (skill-challenge balance). The externalisation process during creativity (i.e., sketching) may therefore facilitate the creative process less in terms of performance advantages, and more through a direct effect on the motivating flow experience.

Csíkszentmihályi (1975; 1990/2002) identified instant, unambiguous feedback as one of the vital factors in flow development. Theoretically, this involves the continual, implicit awareness of successes and failures; confusion about progress is thought likely to disrupt flow. However, the intricacies of what the term 'feedback' entails and how it is acquired cognitively have received little critical attention in the flow literature. Csíkszentmihályi (1996) noted that a defining factor of the feedback system used by creative individuals is the ability to filter good from bad ideas early on in the process. The potential mechanisms that enable this filtering feedback system are the focus of the current study. In particular, we examine the role that moving from internal mental imagery to external (perceptual) selffeedback systems through sketching can play in the experience of flow, and how discrepancies between these feedback systems may also impact on flow. 


\subsection{Creative Performance with MI and Sketching}

Creative ideas often appear first as internal simulacra of perceptual phenomena (Arp, 2005; Moulton \& Kosslyn, 2009), acting as an inner analogue of external forms (Dartnall, 2007). However, no matter how vivid, mental imagery (MI) is merely a simulation, and has been shown previously to have potential limitations. Most famously, Chambers and Reisberg (1985) found that not a single participant was able to see the alternate pattern in Jastrow's (1899) ambiguous duck-rabbit figure using MI only, but all of them could detect the alternate pattern once they externalised the image through drawing. They suggested that MI lacks the same kind of information or is not associated with the same processes as perceptual imaging and therefore does not allow new interpretations to be formed from the same structural pattern. Verstijnen et al. (1998a/b) showed that although MI was sufficient for creative combinations, sketching increased more complex restructuring abilities, resulting in more creative constructions in an experimental analogue of the creative process, the creative mental synthesis task (Finke \& Slayton, 1988).

Others have questioned the theory that MI is insufficient for full, reinterpretive creative cognition and argued that MI is sufficiently like perceptual imagery to allow for the complexities of creative thought (Shepard, 1978). Studies have since provided evidence that there is spatial and temporal equivalence between mental and perceptual imagery (Finke, 1980), that restructuring and reconstrual does frequently occur, and that geometric data are preserved in MI to allow new categorical interpretations to be formed (Finke, Pinker, \& Farah, 1989; Mast \& Kosslyn, 2002; Peterson, Kihlstrom, Rose, \& Glisky, 1992). Wiseman, Watt, Georgiou, and Gilhooly (2011) showed that creative ability was linked to the ability to reinterpret ambiguous mental images mentally, confirming that agility in internally manipulating imagery is a fundamental component of creativity. Beethoven and Monet deaf and blind, respectively, when they created some of their most famous masterpieces - and 
Einstein - who carried out many thought experiments using only his imagination - exemplify in a real-world context that notable creativity does occur without access to or use of perceptual faculties (Garland-Thomson, 2005; Ghiselin, 1952; Harrison, 1988).

Some design researchers suggest that while MI may be sufficient for most creative synthesis, perceptual feedback from sketching can enhance the ability to restructure and reinterpret (Verstijnen et al., 1998a/b). However, others (Anderson \& Helstrup, 1993; Bilda et al., 2006; Kokotovich \& Purcell, 2001) found sketching did not enhance qualitative creative abilities. Evidence that sketching is vital for complex creative restructuring to occur is therefore equivocal and is unlikely to be the only reason why artists and other creators are so reliant on sketching.

There is however an additional translational and dialectical function that occurs on the point of externalisation that is noted repeatedly by creators as a vital part of their process (Ghiselin, 1952; Koestler, 1964). According to Wallas' (1926) classic creative process stages, ideas that form as mental insights must then be verified externally. Therefore, even if creative revision and reinterpretation is equally possible with internal imagery alone, there is an added layer of objectivity and reassurance to be gleaned from perceptual re-evaluation after physical execution of an idea (Simonton, 2011). Sketching may therefore provide a subjective feeling of clarity and certainty about the rightness of one's actions, even when performance is not necessarily objectively enhanced. This was also suggested by participants in Bilda et al.'s (2006) study when they spoke of sketching helping them synthesize and verify MI more clearly and reassure them they were on the right track. Therefore the process of externalisation may provide the kind of unambiguous feedback and assurance about the feasibility of an early idea that is thought to facilitate the flow experience, whereas untested MI remains uncertain and ambiguous. Therefore sketching may help clarify self-feedback and may function as a mechanism behind the filtering feedback system to which 
Csíkszentmihályi (1996) referred, which encourages flow. However, other benefits of sketching may be equally or more important, for instance the unburdening of cognitive resource load.

\subsection{The Impact of Sketching on Cognitive Load}

Anderson and Helstrup (1993, Experiment 2) found that sketching facilitated quantity of production, but not quality, concluding that the main advantage of sketching is to reduce the burden MI places on working memory resources (Kosslyn, 1980; Pearson \& Logie, 2004). Externalising concepts so that they do not need to be continually juggled in working memory therefore may facilitate fluency by freeing up memory resources. This computational offloading was also proposed by Scaife and Rogers (1996) as an important function of sketching, and by the qualitative accounts of the architects in the Bilda et al. (2006) study referring to the image maintenance purpose of externalisation.

In analyses of cognitive activity over the course of the design process with expert architects, Bilda and Gero $(2005 ; 2007)$ found that as time passed, cognitive activity (defined by number of coding categories represented during a think-aloud protocol, including references to physical, perceptual, functional, and conceptual actions) declined in a blindfolded, no-sketch condition significantly more than in the sketching condition. This indicated that sketching helps conserve cognitive resources for more efficient and sustained creating (Anderson \& Helstrup, 1993; Scaife \& Rogers, 1996). The proposed effect of externalisation on cognitive load suggests another way in which components of flow may be affected. Because flow in theory depends on good skill-challenge balance and is characterised by feelings of effortless automaticity, it would generally be more likely to occur when the task is not too mentally taxing. Since effort theoretically is a product of feelings of coping and skills adequate to deal with a certain level of demand, strained demands on working memory resources could therefore tip the skill-challenge balance in favour of 
challenge and thereby hinder the likelihood of flow. Sketching may act to reduce this strain on working memory processes (Pearson \& Logie, 2004; 2014).

\subsection{Potential Confounding Effects of Externalisation: Discrepancy}

However, some research also suggests performance with sketching can in some cases be inferior to MI alone, which may also translate to detrimental effects of sketching on the subjective experience of creating in certain circumstances. Kokotovich and Purcell (2000) found that participants using only MI produced outputs that were judged more creative than those in the sketching condition. Similarly, Verstijnen et al. (1998a) found that in one study an MI condition resulted in better figural synthesis than sketching. Verstijnen et al. argued that there might be a distracting effect of sketching when the task is relatively easy. In contrast to this, Andrade (2009) found that the act of doodling, even when unrelated to a target task, helped to hone attention and enhance memory, suggesting that sketching should have a focusing rather than distracting effect during an easy task.

Research by Neblett, Finke, and Ginsburg (unpublished, as cited in Finke, 1990) found that the presence of another form of external perceptual support (physical shapes which could be moved but not combined or restructured) interfered with the ability to perform mental synthesis at all, because the externalised shapes did not fully reflect internal conceptions. Similarly, in studies of motor action priming and imagery congruence (i.e., grasping an object after either action-congruent or incongruent imagining), action was found to be slowed by incongruent intention imagery (Ramsey, Cumming, Eastough, \& Edwards, 2010). Therefore, perceptual feedback that clarifies and verifies internal conceptions might be helpful to faster, easier generation of ideas. When ideas are re-evaluated perceptually, the limitations of MI may become apparent and cause disruption. Discrepancies between internal predictions and external feedback (representational mismatch: Kavakli \& Gero, 2001) may therefore also play a role in creative flow by introducing ambiguity and expectation violation 
which must be resolved before continuing. The role of perceptual feedback in flow might therefore depend on how well the implementation of an idea succeeds at the point of sensory verification, and the sense of congruence between idea simulations and their physical execution.

\subsection{Study Overview}

In this study, the aim was to bridge the gap between cognitive design research and the motivation, emotion, and flow research to explore whether and why sketching might have a measurable impact on flow experience during visual creativity. Participants performed Finke and Slayton's (1988) creative mental synthesis task (CMST) as an analogue of the visual creative process, either with or without access to sketching, to explore the effects of visual feedback on creative flow. To examine how this interacted with increasing cognitive load, participants also carried out either the traditional three-shape-set task (Finke \& Slayton, 1988) or an expanded version with five shapes (Barquero \& Logie, 1999). Secondary measures of affect change (another measure of subjective experience linked to flow and creating: Akbari Chermahini \& Hommel, 2012; Cseh et al., 2015), performance, sense of task difficulty, idea-execution congruence, and MI vividness were also explored.

\section{Research aims and hypotheses}

\section{Main effects}

Previous research (Anderson \& Helstrup, 1993; Kokotovich \& Purcell, 2000; Neblett et al., as cited in Finke, 1990; Verstijnen et al., 1998a/b) has shown mixed effects of perceptual sketching support on creative performance. Bilda et al. (2006) suggest there is a disconnect between the effect of sketching on performance and creators' reliance on and attitudes toward sketching. The chief benefit of sketching for creators may therefore be how it affects the creators' cognitive-emotional subjective experience of creating. The main prediction of this study was therefore that sketching would facilitate flow. 


\section{Secondary mediating and outcome measures}

The anticipated main effect of feedback support type (MI vs. sketching) on flow was explored in relation to some other potential mediating factors and dependent measures, to aid in interpretation of findings. In particular, main effects of cognitive load increase and interactions between cognitive load and sketching support on flow and other secondary outcome variables (i.e., affect change, self-rated and objective performance, perceived task difficulty, idea-execution congruence) were also explored.

Exploratory correlations were also measured between flow and sense of difficulty, idea-execution congruence, self-rated creativity, and trait imagery vividness, to examine whether these factors might also mediate effects. Partial correlations and a mediation analysis were conducted post-hoc to explore potential inter-relations between variables. Correlations were also measured between flow, affect change, and performance measures.

\section{Method}

\subsection{Participants and Design}

This was a $2 \times 2$ between-subjects study design with two independent variables: 1) feedback support type: CMST carried out either with MI only or with sketching (SK); 2) cognitive load: combining either three or five shapes at a time during the CMST. Eightyeight university students, mostly first- and second-year psychology undergraduates, were randomly allocated to one of four conditions, referred to as 3-MI, 3-SK, 5-MI, or 5-SK. Two additional students who were allocated to the 5-SK condition failed to follow task rules and produced entirely invalid drawings; they were therefore excluded from all analyses. Our sample size was determined in relation to previously published studies on sketching and visual creativity (e.g., Anderson \& Helstrup, 1993; Vertijnen et al., 1998a;b; Pearson \& Logie, 2015), with the sample size chosen to ensure that the number of participants tested in 
each condition equalled or exceeded those specified by previous studies. Data collection ceased once the pre-specified sample size had been reached. Participants were recruited via the department's participation pool for course credit and tested individually or occasionally in non-interactive groups of two to three (all in same condition) in the laboratory. Conditions did not differ significantly in terms of gender or age (see Table 1 for all demographic information).

Table 1. Demographic information by condition (3-MI, 3-SK, 5-MI, 5-SK)

\begin{tabular}{ccc}
\hline $\begin{array}{c}\text { Total }(N=88) \\
\text { Shape Number }\end{array}$ & Ml $(n=45)$ & Feedback Support \\
\hline $\begin{array}{c}\text { S Shapes } \\
(n=42)\end{array}$ & $\begin{array}{c}\text { Age: } M=21.38, S D=4.57 \\
\text { Gender: } 14 \mathrm{~F}, 7 \mathrm{M}\end{array}$ & $\begin{array}{c}3-\mathrm{SK}(n=21) \\
M=21.10, S D=2.53 \\
\text { Gender: } 13 \mathrm{~F}, 8 \mathrm{M}\end{array}$ \\
\hline $\begin{array}{c}5 \text { Shapes } \\
(n=46)\end{array}$ & $\begin{array}{c}5-\mathrm{Ml}(n=24) \\
\text { Age } M=21.25, S D=5.92 \\
\text { Gender: } 16 \mathrm{~F}, 8 \mathrm{M}\end{array}$ & $\begin{array}{c}5-\mathrm{SK}(n=22) \\
\text { Age } M=21.09, S D=5.16 \\
\text { Gender: } 13 \mathrm{~F}, 9 \mathrm{M}\end{array}$ \\
\hline
\end{tabular}

\subsection{Materials and Procedure}

Participants completed several pre- and post-task questionnaires and carried out a modified version of Finke \& Slayton's (1988) CMST (Cseh et al., 2015). The CMST is a paper-and-pen task that involves participants mentally combining simple sets of alphanumeric and geometric shapes (e.g., triangle, letter J, number 8; see Finke \& Slayton or Cseh et al. for full pool of 15 shapes) into a creative new picture of a recognisable object or scene by manipulating the shapes relative to one another according to rules: participants could change the size of the shapes, rotate, flip, overlap or embed the shapes, but could not skew the shape proportions, repeat shapes, or embellish. Participants in this study were given workbooks of 40 shape-sets, with space to produce a written description of the pattern and the drawn pattern beneath each set. Although workbooks deviate from the original Finke and 
Slayton procedure (where sets were presented verbally), workbooks were used here to give uninterrupted concentration time to allow flow to develop. Participants were given 30 minutes to work through the workbook freely, and were able to skip sets and return to skipped sets later. No pressure was placed on them to finish the workbook (which they were told was deliberately too long, to ensure occupation for the full 30 minutes), and they were told to be creative and to try and enjoy the task, to encourage a relaxed atmosphere.

Participants were given a presentation of the upcoming task, and then completed a pre-task Positive and Negative Affect Scale (PANAS; Watson, Clark, \& Tellegen, 1988), a very common mood adjective checklist scale, to gauge pre-task affect. The Vividness of Visual Imagery Questionnaire (VVIQ; Marks, 1973) was administered next, to assess trait vividness of MI (participants are asked to imagine scenarios and rate their subjective similarity to actual perception). Participants then performed the CMST in one of four ways, as follows:

\subsubsection{Experimental factors and conditions.}

\section{Feedback support type (MI vs. sketching).}

Workbooks were modified to accommodate the four conditions of this study. In the MI conditions, participants performed all syntheses mentally and were instructed not to sketch until they had first written down a verbal description of their idea, then drew the image underneath only once, and could not change anything thereafter. This committed them to an idea before they were able to evaluate or reinterpret it perceptually. Participants were only given enough workbook space to draw one final image. The sketching groups, on the other hand, were provided with extra workbook space and were encouraged to sketch freely and continually while generating ideas. Once they had written a description, they too had to commit to one idea/drawing. 


\section{Cognitive load.}

Participants were given a workbook containing either 40 three-shape (regular load) or 40 five-shape (increased load) sets. Sets were semi-randomly generated (see Finke \& Slayton, 1988, for selection process). See Figure 1 for examples of sets and possible responses from each condition.

Figure 1. Example sets for MI vs. SKETCH and 3-Shape vs. 5-Shape Cognitive Load conditions

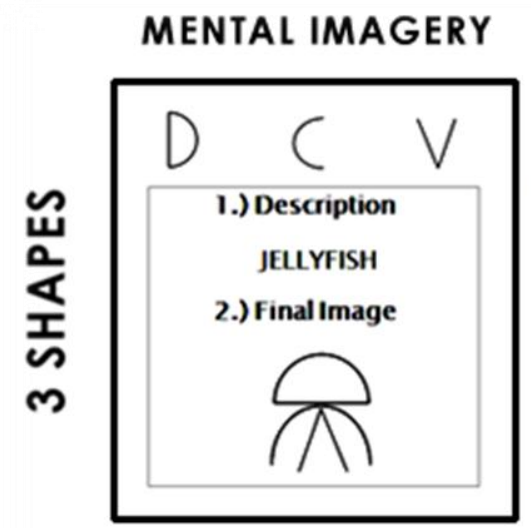

3-MI

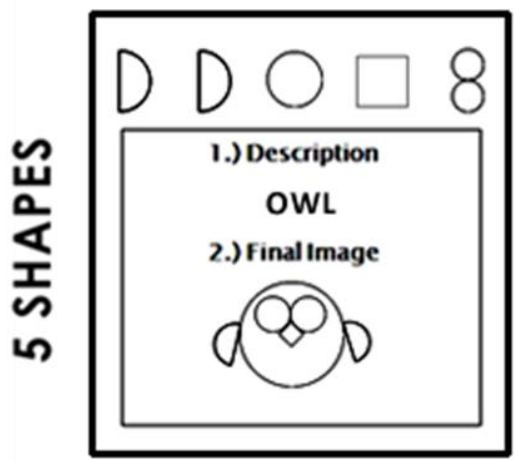

5-MI
SKETCH

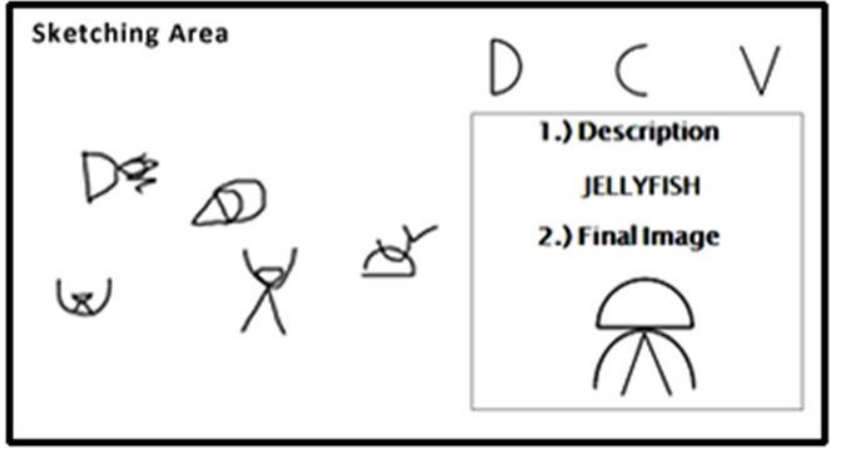

3-SK

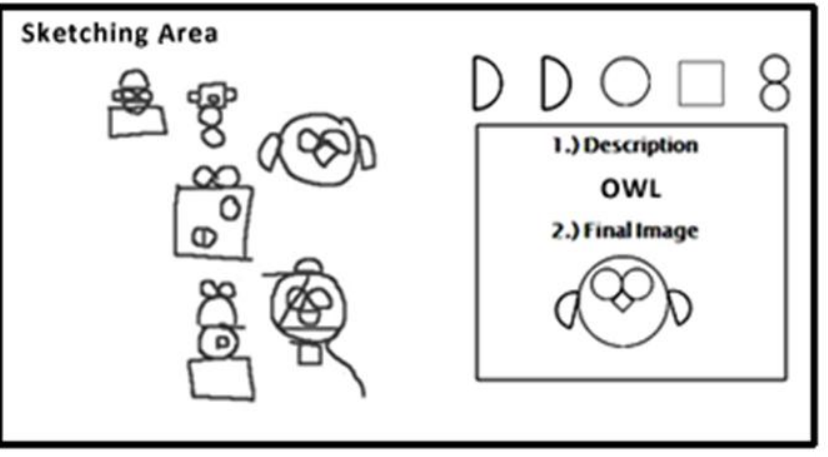

5-SK

\subsubsection{Idea-execution congruence and perceived difficulty.}

To measure the experience of incongruence between mental and perceptual feedback, following each set and before moving on to the next, all participants filled out a one-item idea-execution congruence scale (adapted from Jaarsveld \& van Leeuwen, 2005), answering the question 'How close do you feel your final drawing is to the way you first imagined it?' 
using a 1-4 Likert scale (not at all close - identical) to gauge the level of congruence between the idea generation and final execution stages of their creative process on each trial. A mean was then calculated from all scores per participant.

Afterwards, the booklets were collected and the final questionnaire pack administered. This included the nine-item Flow State Scale - Short General (FSS-2: Jackson, Eklund, \& Martin, 2004/2010), a questionnaire designed to measure experience of each of the nine components of flow (Csíkszentmihályi, 1990/2002; Figure 2), during the immediately

preceding CMST. An example of a

statement from the FSS-2 that

participants rated on a 1 (strongly

disagree) - 5 (strongly agree) Likert

scale, in order to gauge the time

distortion component of flow, is " The

way time passed seemed to be different

from normal."

The PANAS scale was then

repeated, to measure post-task affect and
1. Clear goals

2. Immediate, unambiguous feedback

3. Skill-challenge balance

4. Merging of action \& awareness

5. Total focus on task

6. Sense of control

7. Lack of self-consciousness, no worry of failure

8. Time distortion

9. Autotelic (intrinsically-motivated) experience

Figure 2. The nine traditional components of flow (Csíkszentmihályi, 1990/2002)

to calculate change compared to pre-task affect. Lastly, a post-task questionnaire was given asking participants to rate their own overall creativity on the task and to rate how difficult they found the task (both on 1-5, not at all/slightly-extremely scale). Questionnaires were always presented in the same order.

\subsubsection{Objective performance ratings.}

Participants' drawings were then extracted from the workbooks and rated on two objective creative performance measures by the first author (GC): productivity (the number of complete, valid drawings produced by each participant during the timeframe, as a measure of 
fluency) and transformational complexity (the number of changes the original shape set underwent to form the final construct; this is a count measure of the number of rotations, size changes, and overlaps/embeddings of the shapes in relation to one another and is a measure of mental agility; see Cseh et al., 2015, for full rating procedure and details). The basic rules were the same when calculating the transformational complexity of images produced with either three or five shapes; however, maximum change counts were naturally increased when rating images from the five-shape conditions. Although this is a largely objective measure, some subjectivity can occasionally occur; therefore a random selection of approximately $10 \%$ ( $n=131)$ of the drawings was checked by a second research assistant (blind to conditions). Inter-rater reliability was found to be high $(r(131)=.88, p<.001)$. Although the first author who carried out these ratings was not blind to conditions, this is usually the case, or is not specified (cf. Anderson \& Helstrup, 1993; Palmiero, Cardi, \& Belardinelli, 2011), as it has always been considered an objective change count measure that is conducted systematically and according to rules (as outlined originally by Anderson and Helstrup; additional rules and clarification were also added to ensure a systematic approach and to apply the measure to the more complex five-shape condition: Cseh, 2014); subjectivity can occur, however, in judging, for example, relative size of shapes to one another due to variations in participants' drawing skill. Indeed, the inter-rater agreement check used here is innovative, as no other study to the authors' knowledge using the transformational complexity measure has employed this check previously. The total sample of participants produced 1199 valid images (39/1238 $-3 \%$ - were invalid and excluded from further analysis; $M=13.61$ valid images produced by each participant, $S D=5.81$, range: $5-40$ ). 


\section{Results}

\subsection{Analysis}

A two-way independent-samples ANOVA with sketching support and cognitive load as factors was performed on each dependent variable of interest. Additionally two-tailed Pearson's bivariate correlation analyses were conducted between variables across the sample as a whole. There were no significant differences between conditions on VVIQ scores (MI vs. sketching: $t(83)=-0.84, p=.40 ; 3$ vs. 5 Shapes: $t(83)=0.04, p=.97)$, suggesting groups were matched in terms of average natural ability to conjure MI.

\subsection{Main and Interaction Effects}

\subsubsection{Factor effects on flow and affect change.}

See Table 2 for all descriptive and ANOVA $F$-statistics, partial eta squared effect sizes, and significance levels. First, the main effects of sketching support (MI vs. sketching) and cognitive load (3 vs. 5 shapes) on flow were explored, and the results of the ANOVAs showed that there was a highly significant main effect of sketching support condition on flow scores, with those in the sketching conditions experiencing higher mean flow than the MIonly conditions. However, there was no main effect of cognitive load on flow, and there was no interaction between the two factors on flow.

There were neither main effects of the two factors, nor interaction effects on affect change (either positive (PA) or negative affect (NA) change).

\subsubsection{Factor effects on creative performance.}

To examine how self-rated and objective performance were affected by sketching and by cognitive load, main and interaction effects were also explored in relation to these variables.

\section{Self-rated creativity.}

There were neither main effects nor interaction effects of sketching support or 
cognitive load on self-rated creativity.

\section{Productivity.}

There were significant main effects of both cognitive load and sketching support condition on productivity. The MI conditions produced on average $2.38(p=.03)$ more valid images than the sketching conditions. Significantly fewer images (4.11 fewer on average) were produced overall with five than with three shapes (main effect of cognitive load). However there was no significant interaction between sketching support and cognitive load.

\section{Transformational complexity.}

There was a significant main effect of cognitive load on transformational complexity: drawings produced with five shapes compared to three were, unsurprisingly, more complex. However there was no main effect of sketching support on complexity of drawings, nor an interaction effect of sketching support and cognitive load.

\subsubsection{Factor effects on perceived difficulty, idea-execution congruence.}

There was a main effect of sketching support condition on post-task sense of task difficulty ratings, with the MI conditions rating the task as significantly more difficult than the sketching groups, but no other effects (of cognitive load or an interaction).

There were neither significant main nor interaction effects of sketching support or cognitive load on idea-execution congruence. 
Table 2. Descriptive and ANOVA statistics (cognitive load vs. feedback support type conditions)

\begin{tabular}{|c|c|c|c|c|c|c|c|c|c|c|c|c|c|c|c|c|}
\hline & \multicolumn{7}{|c|}{ Descriptive Statistics } & \multicolumn{9}{|c|}{$2 \times 2$ ANOVA Results } \\
\hline & & \multicolumn{3}{|c|}{3 Shapes } & \multicolumn{3}{|c|}{5 Shapes } & \multicolumn{3}{|c|}{$\begin{array}{l}\text { Main Effect: } \\
\text { Cognitive Load } \\
\text { (3 vs. 5) }\end{array}$} & \multicolumn{3}{|c|}{$\begin{array}{c}\text { Main Effect: } \\
\text { Sketching Support } \\
\text { (MI vs.SKETCH) }\end{array}$} & \multicolumn{3}{|c|}{$\begin{array}{c}\text { Interaction: } \\
\text { Cognitive Load x Feedback } \\
\text { Support Type }\end{array}$} \\
\hline \multicolumn{2}{|l|}{$\begin{array}{l}\text { Dependent } \\
\text { Variable }\end{array}$} & $n$ & $M$ & $S D$ & $n$ & $M$ & $S D$ & $F$ & $\eta^{2}$ & $p$ & $F$ & $\eta^{2}$ & $p$ & $F$ & $\eta^{2}$ & $p$ \\
\hline \multirow{2}{*}{ Flow } & $\mathrm{Ml}$ & 21 & 2.79 & 0.40 & 24 & 2.94 & 0.55 & \multirow{2}{*}{0.00} & \multirow{2}{*}{.00} & \multirow{2}{*}{.95} & \multirow{2}{*}{8.78} & \multirow{2}{*}{.10} & \multirow{2}{*}{$<.01$} & \multirow{2}{*}{1.38} & \multirow{2}{*}{.02} & \multirow{2}{*}{.24} \\
\hline & SK & 21 & 3.30 & 0.64 & 22 & 3.16 & 0.65 & & & & & & & & & \\
\hline \multirow{2}{*}{ PA Change } & $\mathrm{Ml}$ & 21 & -4.76 & 4.57 & 24 & -5.54 & 6.04 & \multirow{2}{*}{0.50} & \multirow{2}{*}{.01} & \multirow{2}{*}{.48} & \multirow{2}{*}{3.05} & \multirow{2}{*}{.04} & \multirow{2}{*}{.08} & \multirow{2}{*}{0.00} & \multirow{2}{*}{.00} & \multirow{2}{*}{.95} \\
\hline & SK & 21 & -2.57 & 4.69 & 22 & -3.50 & 6.93 & & & & & & & & & \\
\hline \multirow{2}{*}{ NA Change } & MI & 21 & 0.81 & 5.28 & 24 & 1.13 & 3.22 & \multirow{2}{*}{0.09} & \multirow{2}{*}{.00} & 70 & 100 & ח0 & 10 & 001 & Pח & \\
\hline & SK & 21 & -0.29 & 2.17 & 22 & -0.09 & 4.53 & & & .10 & 1.80 & .02 & .10 & 0.01 & .00 & .94 \\
\hline Idea-Execution & MI & 21 & 2.61 & 0.38 & 24 & 2.54 & 0.44 & 121 & רח & 27 & 012 & PO & 73 & 006 & Pח & 80 \\
\hline Congruence & SK & 21 & 2.66 & 0.39 & 22 & 2.55 & 0.34 & 1.57 & $.0<$ & 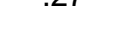 & 0.12 & .00 & 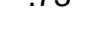 & 0.00 & .00 & .00 \\
\hline Perceived & Ml & 21 & 4.00 & 0.84 & 24 & 3.92 & 1.02 & 0.40 & 01 & 53 & 548 & 06 & $0 ?$ & 104 & 01 & 31 \\
\hline Task Difficulty & SK & 21 & 3.29 & 1.19 & 22 & 3.64 & 0.90 & 0.70 & ז & & & & & דע.1. & ז & r \\
\hline Self-Rated & $\mathrm{Ml}$ & 21 & 2.14 & 0.65 & 24 & 2.21 & 1.18 & קO & Pी & 90 & 110 & ? & 22 & 00 & ( & 76 \\
\hline Creativity & SK & 21 & 2.48 & 1.03 & 22 & 2.41 & 1.14 & 0.00 & .00 & .99 & 1.40 & .02 & .23 & 0.09 & .00 & .16 \\
\hline Productivity & $\mathrm{Ml}$ & 21 & 18.05 & 6.10 & 24 & 11.92 & 4.63 & 1336 & 14 & -001 & 516 & 06 & 03 & 317 & 04 & 08 \\
\hline rocuctivity & SK & 21 & 13.48 & 5.66 & 22 & 11.36 & 4.70 & 10.00 & .14 & $<.001$ & 0.10 & .00 & .00 & 0.11 & .04 & .00 \\
\hline Transform. & MI & 21 & 3.21 & 0.50 & 24 & 6.09 & 0.87 & 21764 & 75 & 001 & 067 & 01 & 12 & 018 & (ח) & 68 \\
\hline Complexity & SK & 21 & 3.14 & 0.53 & 22 & 5.87 & 1.21 & 241.04 & .10 & $<.001$ & 0.01 & .01 & $.4<$ & 0.10 & .00 & .00 \\
\hline
\end{tabular}

Note. Significant results in bold. 
Table 1. Exploratory correlation analyses between flow, affect change, creative performance, and performance experience/imagery acuity variables (two-tailed)

\begin{tabular}{|c|c|c|c|c|c|c|c|c|c|c|}
\hline & & \multirow[b]{2}{*}{ Flow } & \multicolumn{2}{|c|}{$\begin{array}{c}\text { Affect } \\
(N=88)\end{array}$} & \multicolumn{3}{|c|}{ Creative Performance $(N=88)$} & \multicolumn{3}{|c|}{$\begin{array}{c}\text { Performance Experience \& } \\
\text { Imagery Acuity }\end{array}$} \\
\hline & & & $\begin{array}{c}\text { PA } \\
\text { Change }\end{array}$ & $\begin{array}{c}\text { NA } \\
\text { Change }\end{array}$ & $\begin{array}{l}\text { Self-Rated } \\
\text { Creativity }\end{array}$ & Productivity & $\begin{array}{l}\text { Transform. } \\
\text { Complexity }\end{array}$ & $\begin{array}{c}\text { VVIQ } \\
(N=85)\end{array}$ & $\begin{array}{c}\text { Idea- } \\
\text { Execution } \\
\text { Congruence }\end{array}$ & $\begin{array}{l}\text { Sense of } \\
\text { Task } \\
\text { Difficulty }\end{array}$ \\
\hline & Flow & - & $.41^{\star * \star}$ & -.19 & $.61^{\star \star \star}$ & .09 & .15 & $.24^{\star}$ & $.27^{\star}$ & $-.59^{\star \star \star}$ \\
\hline \multirow{2}{*}{$\begin{array}{l}\text { Affect } \\
(N=88)\end{array}$} & PA Change & - & - & -.11 & $.25^{\star}$ & -.04 & -.04 & $.22^{\star}$ & .04 & $-.27^{\star}$ \\
\hline & NA Change & - & - & - & $-.23^{\star}$ & -.14 & -.02 & -.10 & $-.30^{\star \star}$ & .16 \\
\hline \multirow{3}{*}{$\begin{array}{c}\text { Creative } \\
\text { Performance } \\
(N=88)\end{array}$} & $\begin{array}{l}\text { Self-Rated } \\
\text { Creativity }\end{array}$ & - & - & - & - & .12 & .12 & $.29^{\star \star}$ & $.35^{\star \star}$ & $-.52^{\star \star \star}$ \\
\hline & Productivity & - & - & - & - & - & $-.26^{\star}$ & .03 & .12 & -.15 \\
\hline & $\begin{array}{l}\text { Transform. } \\
\text { Complexity }\end{array}$ & - & - & - & - & - & - & .02 & .01 & -.04 \\
\hline \multirow{3}{*}{$\begin{array}{l}\text { Performance } \\
\text { Experience \& } \\
\text { Imagery } \\
\text { Acuity }\end{array}$} & $\begin{array}{c}\text { VVIQ } \\
(N=85)\end{array}$ & - & - & - & - & - & - & - & .20 & $-.28^{\star \star}$ \\
\hline & $\begin{array}{l}\text { Idea-Execution } \\
\text { Congruence }\end{array}$ & - & - & - & - & - & - & - & - & $-.34^{\star \star}$ \\
\hline & $\begin{array}{l}\text { Sense of Task } \\
\text { Difficulty }\end{array}$ & - & - & - & - & - & - & - & - & - \\
\hline
\end{tabular}

Note. Significant correlations in bold; * indicates significant at $p<.05 ;{ }^{* *}$ significant at $p<.01 ;{ }^{* * *}$ significant at $p<.001$ 


\subsection{Correlations and Mediation Analyses}

See Table 3 for all correlation coefficients and significance levels. Flow was strongly, negatively related to sense of task difficulty. Flow was also positively and significantly correlated with idea-execution congruence and trait MI vividness (VVIQ scores). Flow was also strongly correlated with PA increase and self-rated creativity, but not related to either objective measure of performance, replicating the previous findings of Cseh et al. (2015).

Positive affect (PA) change (increase) was also negatively correlated with perceived task difficulty, but the positive relationship between perceived task difficulty and negative affect (NA) change (increase) was not significant. There was a significant correlation between idea-execution incongruence and NA increase, but no correlation between congruence and PA change.

Idea-execution congruence was negatively correlated with sense of task difficulty and positively related to self-rated creativity, but not to trait MI vividness (though this approached significance: $p=.07$ ). Sense of task difficulty was negatively related to vivid trait MI and to self-rated creativity. Vivid MI was significantly correlated with self-rated creativity, but not to either of the objective performance measures.

\subsubsection{Mediation analysis and partial correlations.}

Because of the significant impact of sketching on both flow and participants' perception of task difficulty, as well as the significant correlation between flow and perceived difficulty, a mediation analysis was conducted to determine if perceived difficulty (the rating of how difficult participants found the CMST, post-task) mediated the effect of sketching on flow. The mediation analysis was conducted according to methods detailed by Preacher and Hayes (2004; 2008), using the 'INDIRECT' SPSS syntax macro provided by Hayes (2013), which performs a series of regression analyses between variables, see Figure 3 . In this case the relationship between the predictor and outcome $\left(\mathrm{c}=.35^{* *}\right)$ is reduced to below 
significance $\left(\mathrm{c}^{\prime}=.20\right)$ once the mediator is included in the regression model. The significance of the mediation effect was determined via bootstrapping with 5000 resamples. Significant mediation effects $($ at $\mathrm{p}<.05)$ are indicated when lower and upper confidence intervals (CIs) of the bootstrap values do not include zero (which is the case here: Lower CI $=0.02$, Upper $\mathrm{CI}=0.33$ ) and the indirect relationships (Paths $a$ and $b$ in Figure 3) are significant; see Preacher \& Hayes, 2004; 2008). Since both of these conditions were satisfied in this mediation analysis, it can be concluded

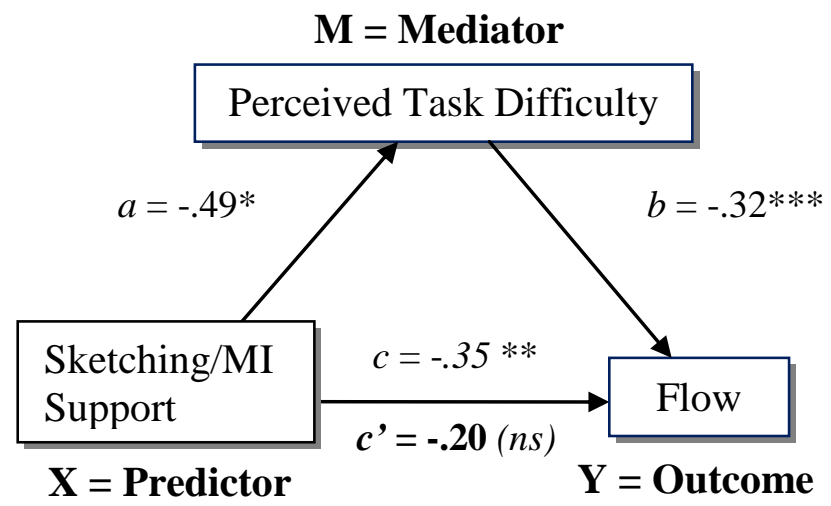

Figure 3. Diagram of mediation analysis between sketching/MI support condition, flow, and perceived task difficulty $\left({ }^{*} p<.05\right.$, $\left.{ }^{* *} p<.01,{ }^{* * *} p<.001\right)$. An initial regression examines the relationship between the predictor and the potential mediator variable (path a). The second step confirms the direct relationship between the predictor variable and the dependent variable (path $c)$. The last regression analysis simultaneously enters the mediator and predictor variables to explain variance in the dependent variable (paths $b$ and $c^{\prime}$ ). Path coefficients are uncorrected, as recommended by Preacher and Hayes (2008).

that perceived task difficulty was a significant mediator in the relationship between sketching and flow.

Since cognitive load did not influence either flow or perceived difficulty, partial correlations were carried out between flow and perceived difficulty, controlling for other variables. The aim was to determine which other factors might be influencing the link between flow and difficulty, both of which had been similarly affected by sketching.

The first partial correlation between flow and perceived difficulty controlled for ideaexecution congruence. However, the relationship remained highly significant $(r(85)=-.55$, $p<.001)$, therefore idea-execution congruence does not appear to be a significant factor in the link between flow and perceived task difficulty. Secondly, a partial correlation was 
conducted between flow and perceived difficulty, controlling for self-rated creativity, but this relationship also remained significant $(r(85)=-.40, p<.001)$. Lastly, a partial correlation was conducted controlling for trait MI vividness (VVIQ scores), but this too remained significant $(r(82)=-.58, p<.001)$. Results therefore do not support the possibility that the link between flow and perceived difficulty is mediated by idea-execution congruence, selfperceived creativity, or trait MI vividness.

\section{Discussion}

This study explored whether a significant benefit of sketching in the creative process is its positive motivational effect on the subjective cognitive-emotional experience of creating, by facilitating flow. Secondary aims were to investigate some potential reasons behind this effect by examining factors related to perceived advantages of sketching outlined by previous researchers (Anderson \& Helstrup, 1993; Bilda \& Gero, 2005; 2007; Bilda et al., 2006; Scaife \& Rogers, 1996; Verstijnen et al., 1998a/b), including lightening of cognitive/memory resource load, disambiguating mental feedback, and effects on feelings of competence and affect. Results support the main hypothesis by showing a significant impact of sketching on increased flow via a lowered sense of task difficulty, though there was no significant advantage in terms of affect change or creative performance. The significant facilitating influence of sketching on flow and feelings of ease, but not creative performance, could help to explain the disparity that has been noted between artists' and designers' dependence on sketching and its lack of a strong impact on performance (Bilda et al., 2006). Bilda et al. found that architects believed sketching helped them perform better, preserve working memory space, and more clearly synthesize and verify mental images. However, these were only perceived advantages which were not reflected in, for example, more creatively synthesized or feasible ideas. The results of the current study show a similar 
pattern.

In this study three factors similar to those highlighted by Bilda et al. (2006) and others (e.g., Kavakli and Gero, 2001; Neblett et al., in Finke, 1990) were explored in relation to how they might impact on flow: creative performance (self-perceived and objective measures), cognitive (working memory) load, and idea-execution congruence (disparity upon translation from internal to external perceptual feedback). All three were believed to have potential links to sense of task difficulty and trait MI vividness, which were also explored as possible influential variables in flow formation within visual creativity.

\subsection{Self-Perceptions and Objective Creative Performance}

Flow was shown both in this study and in an earlier study (Cseh et al., 2015) to be highly correlated with self-ratings of creativity, confirming again that self-concept about skill is important in relation to flow. Bilda et al. (2006) did not formally measure self-perceptions about performance in their study with architects. However, architects were reported to invariably believe they would be unable to design effectively without access to sketching; however, measures of design creativity and practicality were equal with or without sketching. The results of the current study also show a lack of difference in objective performance between sketching support conditions.

Since sketching increases flow, when someone sketches they would be more likely to enjoy the creative process and experience a good fit between their skills and the demands of the task. Therefore it was considered likely that creators allowed to sketch could in turn be more likely to rate their creative ability higher than those not allowed to sketch, which could, again, influence flow in a cyclical, upward spiral. However, since sketching did not appear to influence self-perceived creativity ratings in this study, this does not account for the effect of sketching on flow.

Sketching did not improve objective performance, which is in line with the findings of 
Bilda et al.'s (2006) study and their conclusion that sketching mainly helps provide feelings of ease rather than true facilitation of processes needed to perform more creatively. If anything, in the current study the MI-only conditions fared slightly better overall, having significantly higher productivity and marginally (though non-significantly) higher transformational complexity ratings.

The finding that sketching did not improve productivity at first glance may appear to contradict those of Anderson and Helstrup (1993, Experiment 2), who found that sketching increases the number of patterns that are produced in a timeframe. However, the procedure followed by Anderson and Helstrup was quite different - they were comparing fluency of producing variations on a theme, within a limited timeframe imposed on each set. In the current study, participants worked on a workbook of discrete sets, producing only one final image for each set, and with no time limits imposed on each set. Task instructions told participants not to worry about completing the workbook and to have fun; this may have resulted in participants not being particularly focused on speed of production. The sketching participants may therefore have spent more time exploring more options before settling on their final images and moving on, thereby limiting the number of sets they could complete in the timeframe. Therefore in this study the higher number of sets completed by the MI conditions compared to the sketching conditions likely reflects that drawing out ideas, practically speaking, takes longer than simply imagining them, rather than signaling an effect on cognitive processing speed.

\subsection{Perceived Difficulty, Skill-Challenge Balance, and Cognitive Load}

Sketching significantly increased flow and decreased perceived task difficulty, and the mediation analysis suggests that decreasing perception of difficulty is an important function that sketching likely serves in the development of flow. This supports Bilda et al.'s (2006) conclusion that sketching makes the design process seem easier, even when it resulted in 
equal performance outcomes. In their study, Bilda et al. referred to this easing of perceived difficulty being a result of generally lightened loads on the cognitive processes required in the creative process, including on memory resources. However, in the current study the relationship between flow and perceived task difficulty was independent of objective cognitive load increase, and unmediated by other factors thought to potentially contribute to sense of effort, such as idea-execution congruence, trait vividness of MI, or self-ratings of creative ability.

The only factor shown here to impact on perceived difficulty was sketching; the reasons behind that effect need to be further explored. Interestingly, sketching facilitated flow but did not impact on affect change, which has been previously shown to have strong ties to flow in Cseh et al. (2015), and which was a repeated finding in this study. Flow has both cognitive and emotional aspects to it, though the distinction and relationships between these categories of components can be unclear (de Manzano, Theorell, Harmat, \& Ullén, 2010). This lack of an impact of sketching on affect, while still influencing flow, signals that sketching influences the specifically cognitive components of flow while leaving affective variables - as well as factors influencing both objective and self-perceptions about creative skill - unaffected.

Skill-challenge balance is considered the core of flow theory, with the concept of 'challenge' inherently based on a sense of perceived 'difficulty' or perceived task 'demands'. Landhäußer and Keller (2012) noted that 'challenge' refers to a personal subjective comparison of how well one's skills are able to cope with the demands of the task, and perceived difficulty also has this connotation. Therefore perceived difficulty should not be confused with objective demands. Efklides, Samara, and Petropoulou (1999) note that although objective task demands and perceived difficulty are often related, they are not perfectly mirrored, as perception depends on various factors, including individual differences 
in ability, and affect.

Bilda et al. (2006) suggested that one of the ways that sketching may support the creative process is by reducing strain on working memory resources and by supporting image maintenance. Theoretically if a task becomes objectively more difficult, one would expect more errors to occur in its performance, and in past research, increases in cognitive load through manipulation of shape number in the CMST (e.g., Barquero \& Logie, 1999) have shown that participants do produce more invalid images when they have to combine a higher number of shapes. This was also reflected to an extent in the current study by the lower number of images produced overall with five compared to three shapes, suggesting a slowing down of processes with additional cognitive load. However, flow and perceived difficulty were only significantly affected by what kind of cognitive feedback participants had access to during idea generation - perceptual or mental. The finding that sketching does not help more as task complexity increases is one also found by Verstijnen et al. (1998b), where the beneficial effect of sketching was only found when particularly complex shapes (a threedimensional diamond) were excluded. The current study has therefore identified one specific factor that can influence perception of difficulty, namely sketching, and found that this effect is independent of cognitive load in terms of working memory capacity strain, which may play less of a role in creative flow than previously assumed.

\subsection{Feedback Ambiguity, Congruence, and MI Vividness}

If not cognitive load, what other factors then might sketching be influencing in relation to sense of difficulty and flow? Efklides, Papadaki, Papantoniou, and Kiosseoglou (1998) suggest that feelings of difficulty may depend on a great many inter-relating characteristics of the individual and the task, but that one particular factor may be people's own conceptions of their previous experiences and abilities with similar problems and the ease with which they are able to draw on memory resources. In a creativity task, these 
factors may relate to MI acuity and discrepancies between expectations and outcomes of performance.

In this study, how access to perceptual feedback through sketching may affect creative flow was also explored in relation to whether it might reduce a sense of feedback ambiguity while creating. Since MI is a limited simulation, the feedback a creator may get using MI alone may not be very complete. As Chambers and Reisberg (1985) and Verstijnen et al. (1998a/b) demonstrated, there are potential limitations to MI, particularly to resolving structural ambiguities. Externalising and re-evaluating an idea with the aid of sketches may clarify and elaborate on MI, disambiguating feedback about the value and feasibility of an idea. If so, sketching during idea generation might result in a closer match between an idea and its final execution. Being unable to perceptually test ideas (MI conditions) could engender a sense of increased discord between an initial image and the reality on paper. At this point, ideas can be perceptually reinterpreted and potentially found to have been misleading (idea-execution incongruence), a factor shown to sometimes have a confounding influence on cognitive processes (Neblett et al., in Finke, 1990; Ramsey et al., 2010). However, sketching does not seem to have significantly helped to resolve discrepancy between an initial concept and the execution of it, as there was no effect of sketching on ideaexecution congruence. However, idea-execution congruence was found to be significantly related both to perceived task difficulty and to flow, but did not mediate the link between flow and perceived difficulty. Therefore, it does not appear that resolving a sense of discrepancy is mainly responsible for why sketching reduces perceived difficulty or how difficulty is related to flow.

Although idea-execution congruence was significantly correlated with flow, it was not, however, linked to positive affective change. The exception was NA increase, which was significantly related to incongruence. The fact that some variables, such as productivity 
(linked to PA change but not flow in our previous study reported in Cseh et al., 2015), and idea-execution congruence here, relate differently to flow and PA change once again signals a distinction between cognitive and emotional aspects of flow and between flow and PA. Therefore a more clear distinction between which parts of the flow experience are emotionbased, and which are cognitive, is required.

The findings in the current study partly support the findings of Wiseman et al. (2011), who found that MI acuity was linked to both self-perceived trait creativity and objective measures of creative flexibility and fluency. In the current study vivid MI did not relate to objective measures of performance, including transformational complexity, which is theoretically a measure of structural reconfiguration and agility. However, general vividness of imagery in the current study was related to several measures of subjective experience of performance, including self-belief in creative ability, perception of task difficulty, and (marginally) to idea-execution congruence. Vividness of MI, which is measured in terms of mainly static imagery, may be different to MI agility or control, however, as measured by figure reversal ability in Wiseman et al., which may be responsible for the difference in findings about objective performance. Subjective clarity of MI does, however, seem to be significantly linked to how subjectively pleased creators were by their own perceived creative performance, feelings of difficulty during the task, and flow.

The links found between idea-execution, vivid MI, perceived difficulty, and flow, and the lack of effects from cognitive load may suggest that clarity of mental feedback plays a greater role in how the creative process is experienced than cognitive load does, in terms of juggling increasing demands on working memory. Although the current study found links from trait MI vividness and idea-execution congruence to both flow and perceived task difficulty, sketching only had a direct impact on flow via perceptions of difficulty and did not influence congruence between ideas and physical executions. Trait MI vividness, idea- 
execution congruence, and self-rated creativity also could not explain the link between flow and perceived difficulty. So although MI vividness and internal-external or expectationoutcome congruence are some part of flow and perceived difficulty, they are not the specific aspects of these variables that sketching affects.

There may of course be other factors contributing to the effect of sketching on flow and perception of difficulty, such as the benefits of physical embodiment in drawing and artmaking (Banfield \& Burgess, 2013) or its influence on attentional focus (Andrade, 2009). Indeed effects of sketching on flow could be further explored in relation to several of the other flow components such as sense of control and merged action and awareness (Figure 2; Csíkszentmihályi, 1990/2002), which suggests a new avenue for future flow and creativity researchers to explore.

\section{Conclusion}

This study has demonstrated for the first time that it is possible to measurably improve the experience of flow by experimentally improving access to perceptual feedback via sketching during visual creativity. Results of this study suggest that sketching affects flow by reducing sense of effort, but that this relationship between flow and perceived difficulty is not a function of objective demands on working memory resources (cognitive load), nor is it linked to idea-execution congruence, self-perceived creativity, or trait MI vividness. Although these specific variables were ruled out in the effect of sketching on flow, clarity of mental feedback and self-concept do appear to be more closely related to the subjective experience of creative flow than cognitive load.

This study showed that sketching during the creative process facilitates flow by decreasing perceived effort; therefore sketching can be seen as a motivating influence on the creative process which could encourage perseverance and more frequent practice and 
therefore faster attainment of goals and mastery. Further research is needed to better understand the specific conditions of the creative process that influence perception of difficulty and how sketching may arbitrate that link to encourage flow. 


\section{References}

Akbari Chermahini, S., \& Hommel, B. (2012). Creative mood swings: Divergent and convergent thinking affect mood in opposite ways. Psychological Research, 76, 634640. doi:10.1007/s00426-011-0358-z

Anderson, R. E., \& Helstrup, T. (1993). Visual discovery in mind and on paper. Memory and Cognition, 21(3), 283-293. doi: 10.3758/BF03208261

Andrade, J. (2009). What does doodling do? Applied Cognitive Psychology, 64(1), 100-106. doi:10.1002/acp.1561

Arp, R. (2005). Scenario visualization: One explanation of creative problem solving. Journal of Consciousness Studies, 12(3), 31-60.

Banfield, J., \& Burgess, M. (2013). A phenomenology of artistic doing: Flow as embodied knowing in 2D and 3D professional artists. Journal of Phenomenological Psychology, 44(1), 60-91. doi:10.1163/15691624-12341245.

Barquero, B., \& Logie, R. H. (1999). Imagery constraints on quantitative and qualitative aspects of mental synthesis. European Journal of Cognitive Psychology, 11(3), 315333. doi:10.1080/713752318

Bilda, Z., \& Gero, J. S. (2005). Does sketching off-load visuo-spatial working memory? In J. S. Gero \& N. Bonnardel (Eds.), Studying designers '05 (pp. 145-159). Sydney, Australia: Key Centre of Design Computing and Cognition, University of Sydney.

Bilda, Z., \& Gero, J. S. (2007). The impact of working memory limitations on the design process during conceptualization. Design Studies, 28(4), 343-367. doi:10.1016/j.destud.2007.02.005

Bilda, Z., Gero, J. S., \& Purcell, T. (2006). To sketch or not to sketch? That is the question. Design Studies, 27(5), 587-613. doi:10.1016/j.destud.2006.02.002

Chambers, D., \& Reisberg, D. (1985). Can mental images be ambiguous? Journal of 
Experimental Psychology: Human Perception and Performance, 11(3), 317-328. doi:10.1037//0096-1523.11.3.317

Cseh, G. M. (2014). Flow in visual creativity (Unpublished doctoral dissertation). University of Aberdeen, Scotland, United Kingdom.

Cseh, G. M., Phillips, L. H., \& Pearson, D. G. (2015). Flow, affect, and visual creativity. Cognition and Emotion, 29(2), 281-291. doi:10.1080/02699931.2014.913553

Csíkszentmihályi, M. (1975). Beyond boredom and anxiety. San Francisco, CA: Jossey-Bass. Csíkszentmihályi, M. (1996). Creativity: Flow and the psychology of discovery and invention. New York, NY: Harper Perennial.

Csíkszentmihályi, M. (2002). Flow: The classic work on how to achieve happiness (Rev. ed.). London, England: Rider.

Dartnall, T. (2007). Internalism, active extemalism, and nonconceptual content: The ins and outs of cognition. Cognitive Science, 31(2), 257-283.

de Manzano, O., Theorell, T., Harmat, L., \& Ullén, F. (2010). The psychophysiology of flow during piano playing. Emotion, 10(3), 301-311.

Efklides, A., Papadaki, M., Papantoniou, G., \& Kiosseoglou, G. (1998). Individual differences in feelings of difficulty: The case of school mathematics. European Journal of Psychology of Education, 13(2), 207-226.

Efklides, A., Samara, A., \& Petropoulou, M. (1999). Feeling of difficulty: An aspect of monitoring that influences control. European Journal of Psychology of Education, XIV(4), 461-476.

Efland, A. (1990). A history of art education: Intellectual and social currents in teaching the visual arts. New York, NY: Teachers College Press.

Finke, R. A. (1980). Levels of equivalence in imagery and perception. Psychological Review, 87, 113-132. 
Finke, R. A. (1990). Creative imagery: Discoveries and inventions in visualization. Hillsdale, NJ: Laurence Erlbaum Associates.

Finke, R. A., \& Slayton, K. (1988). Explorations of creative visual synthesis in mental imagery. Memory and Cognition, 16(3), 252-257.

Finke, R. A., Pinker, S., \& Farah, M. J. (1989). Reinterpreting visual patterns in mental imagery. Cognitive Science, 13, 51-78.

Garland-Thomson, R. (2005). Disability and representation. PMLA, 120(2), 522-527.

Ghiselin, B. (1952). The creative process: A symposium. Berkeley: University of California Press.

Harrison, P. (1988). The effects of deafness on musical composition. Journal of the Royal Society of Medicine, 81, 598-601.

Hayes, A. F. (2013). SPSS 'INDIRECT' macro syntax and reference. Retrieved from http://www.afhayes.com/spss-sas-and-mplus-macros-and-code.html

Jaarsveld, S., \& van Leeuwen, C. (2005). Sketches from a design process: Creative cognition inferred from intermediate products. Cognitive Science, 29(1), 79-101. doi:10.1207/s15516709cog2901_4

Jackson, S. A., Eklund, R. C., \& Martin, A. (2010). The flow manual: The manual for the flow scales. Menlo Park, CA: Mind Garden.

Jastrow, J. (1899). The mind's eye. Popular Science Monthly, 54, 299-312.

Kavakli, M., \& Gero, J. (2001). Sketching as mental imagery processing. Design Studies, 22(4), 347-364.

Kleiner, F. S. (2014). Gardner's art through the ages: A concise western history (3rd Ed.). Boston, MA: Wadsworth.

Koestler, A. (1964). The act of creation. London, England: Hutchinson.

Kokotovich, V., \& Purcell, T. (2000). Mental synthesis and creativity in design: An 
experimental examination. Design Studies, 21, 437-449.

Kosslyn, S. M. (1980). Image and mind. Cambridge, MA: Harvard University Press.

Landhäußer, A., \& Keller, J. (2012). Flow and its affective, cognitive, and performancerelated consequences. In S. Engeser (Ed.), Advances in flow research (pp. 65-86). New York, NY: Springer. doi:10.1007/978-1-4614-2359-1_4

Marks, D. F. (1973). Visual imagery differences in the recall of pictures. The British Journal of Psychology, 64(1), 17-24. doi:10.1111/j.2044-8295.1973.tb01322.x

Maslow, A. H. (1959). Cognition of being in the peak experiences. The Journal of Genetic Psychology, 94, 43-66.

Mast, F. W., \& Kosslyn, S. M. (2002). Visual mental images can be ambiguous: Insights from individual differences in spatial transformation abilities. Cognition, 86(1), 5770.

Moulton, S. T., \& Kosslyn, S. M. (2009). Imagining predictions: Mental imagery as mental emulation. Philosophical Transactions of the Royal Society of London: Series B, Biological Sciences, 364, 1273-1280. doi:10.1098/rstb.2008.0314

Palmiero, M., Cardi, V., \& Belardinelli, M. O. (2011). The role of vividness of visual mental imagery on different dimensions of creativity. Creativity Research Journal, 23(4), 372-375. doi:10.1080/10400419.2011.621857

Pearson, D. G., \& Logie, R. H. (2004). Effects of stimulus modality and working memory load on mental synthesis performance. Imagination, Cognition, and Personality, 23(2/3), 183-192.

Pearson, D. G., \& Logie, R. H. (2014). A sketch is not enough: Dynamic external support increases creative insight on a guided synthesis task. Thinking and Reasoning. Advance online publication. doi:10.1080/13546783.2014.897255

Peterson, M. A., Kihlstrom, J. F., Rose, P. M., \& Glisky, M. L. (1992). Mental images can be 
ambiguous: Reconstruals and reference-frame reversals. Memory and Cognition, 20(2), 107-23.

Preacher, K. J., \& Hayes, A. F. (2004). SPSS and SAS procedures for estimating indirect effects in simple mediation models. Behavior Research Methods, Instruments, and Computers, 36, 717-731.

Preacher, K. J., \& Hayes, A. F. (2008). Asymptotic and resampling strategies for assessing and comparing indirect effects in multiple mediator models. Behavior Research Methods, 40(3), 879-891. doi:10.3758/BRM.40.3.879

Privette, G., \& Bundrick, C. M. (1991). Peak experience, peak performance, and flow: Correspondence of personal descriptions and theoretical constructs. Journal of Social Behavior and Personality, 6(5), 169-188.

Ramsey, R., Cumming, J., Eastough, D., \& Edwards, M. G. (2010). Incongruent imagery interferes with action initiation. Brain and Cognition, 74(3), 249-54. doi:10.1016/j.bandc.2010.08.005

Scaife, M., \& Rogers, Y. (1996). External cognition: How do graphical representations work? International Journal of Human-Computer Studies, 45(2), 185-213. doi:10.1006/ijhc.1996.0048

Shepard, R. N. (1978). The mental image. American Psychologist, 33(2), 125-137.

Simonton, D. K. (2011). Creativity and discovery as blind variation: Campbell's (1960) BVSR model after the half-century mark. Review of General Psychology, 15(2), 158174. doi:10.1037/a0022912

Verstijnen, I. M., Hennessey, J. M., van Leeuwen, C., Hamel, R., \& Goldschmidt, G. (1998a). Sketching and creative discovery. Design Studies, 19(4), 519-546. doi:10.1016/S0142-694X(98)00017-9

Verstijnen, I. M., van Leeuwen, C., Goldschmidt, G., Hamel, R., \& Hennessey, J. M. 
(1998b). Creative discovery in imagery and perception: combining is relatively easy, restructuring takes a sketch. Acta Psychologica, 99(2), 177-200.

Wallas, G. (1926). The art of thought. London, England: Butler \& Tanner Ltd.

Watson, D., Clark, L. A., \& Tellegen, A. (1988). Development and validation of brief measures of positive and negative affect: The PANAS scales. Journal of Personality and Social Psychology, 54(6), 1063-70. doi:10.1037/0022-3514.54.6.1063

Wiseman, R., Watt, C., Gilhooly, K., \& Georgiou, G. (2011). Creativity and ease of ambiguous figural reversal. British Journal of Psychology, 102, 615-22. doi:10.1111/j.2044-8295.2011.02031.x 